\title{
УДК 697.9
}

\section{К выбору схемы распределения воздуха от систем вентиляции и кондиционирования в зале малого крытого ледового катка}

\author{
Русаков C.B. rsvit@mail.ru \\ ООО «РУСБЭНЕРГОМОНТАЖ» \\ 190020, Россия, Санкт-Петербург, Старо-Петергофский пр., д.22
}

\begin{abstract}
В работе рассматривается влияние схемы распределения воздуха от систем вентиляции и кондиционирования на характеристики полей температуры и влажннсти над поверхностью ледовой площадки в условиях крытого ледового катка. Раскрывается влияние подвижности воздуха на распределение параметров надо льдом, а также на состояние ледовой поверхности. Приводятся графики изменения температуры воздуха над ледовой площадкой по высоте, сформированные в процессе теплообмена по результатам замеров автора и из других источников. Представлен график изменения влагосодержания воздуха на основе данных, полученных автором, иллюстрирующий интенсивность массообмена. Предлагается к применению схема распределения воздуха, опробованная на ряде объектов, исключающая прямое влияние воздуиных струй на ледовый массив. Приводится методика расчета предлагаемой схемы с учетом обеспечения нормируемой подвижности воздуха надо льдом.
\end{abstract}

Ключевые слова: ледовый каток, ледовая арена, вентиляция и кондиционирование ледовых катков, тепломассообмен у ледовой поверхности, распределение воздуха в зале ледового катка.

DOI: $10.17586 / 2310-1148-2017-10-2 / 3-26-34$

\section{The choice of the scheme of air distribution from ventilation and air-conditioning systems in the hall of the small indoor ice rink}

\author{
Rusakov S.V.rsvit@mail.ru \\ RUSENERGOMONTAZH Ltd \\ 190020, St. Petersburg, Russia, Ave. Staro-Petergofsky, 22
}

This paper examines the impact of the scheme of air distribution from ventilation and air conditioning systems on the characteristics of the fields of temperature and humidity over the ice surface areas in the indoor ice rink. Reveals the influence of air movement on the distribution of parameters over the ice, and on the condition of the ice surface. Graphs of air temperature over the ice platform height, formed in the heat exchange process the results of measurements of the author and from other sources. Presents a graph of the moisture content of the air on the basis of data obtained by the author, illustrating the intensity of mass transfer. It is proposed to use the scheme of air distribution, tested on a number of sites, excluding the direct impact of air jets on the ice array. The design procedure of the proposed scheme taking into account ensure the necessary air movement over the ice.

Keywords: ice rink, ice arena, ventilation and air conditioning of ice rinks, heat and mass transfer at the ice surface, the air distribution in the hall of the ice rink.

За последние годы в России построено немало крытых ледовых катков различного назначения. Накоплен значительный опыт проектирования, строительства и эксплуатации ледовых арен.

Между тем по-прежнему ощущается серьезный недостаток доступных методических материалов, основанных на накопленном опыте, дающих проектировщикам инструменты для применения эффективных решений по инженерному оснащению таких объектов.

Зал ледового катка является уникальным по совокупности происходящих физических процессов, в доступной справочной литературе отсутствуют методики для расчетов некоторых из них. Система кондиционирования воздуха ледового зала требует применения специальных решений, привычные схемы здесь не работают. Отсутствие знаний и опыта у проектировщиков приводит к ошибкам, которые в лучшем случае ухудшают энергетические характеристики объекта, а в худшем делают зал полностью непригодным для занятий спортом, с туманом в объеме, конденсатом на конструкциях или запредельной концентрацией углекислого газа в воздухе.

Одна из часто встречающихся ошибок заключается в неправильных решениях по распределению воздуха в объеме, граничащем с ледовой поверхностью. Так, например, считается «очень важным обеспечить 
распределение приточного воздуха при условии полного перекрытия струями поверхности льда. Эти струи долюны быть достаточно нагреты, чтобы компенсировать конвективные потоки тепла от воздуха к поверхности льда. На участках, к которым такой воздух не поступает, может образоваться туман и происходит конденсация водяных паров из воздуха, что недопустимо по условиям сохранения качественной поверхности льда...» Рекомендованная для выполнения этого требования схема распределения воздуха представлена на рис. 1.

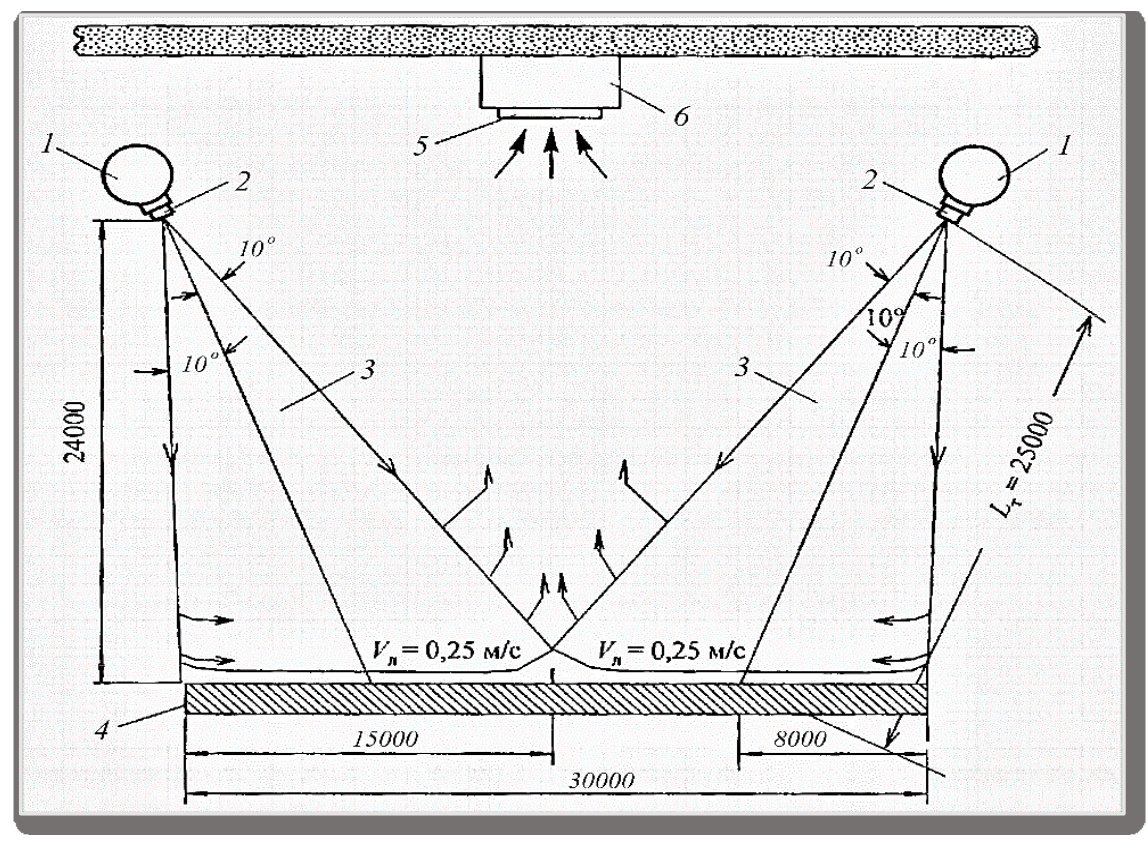

Рис. 1. Принципиальная схема распределения воздуха, основанная на заполнении зоны ледового поля

В соответствии со схемой приточный воздух подается в зону льда из дальноструйных сопел (2), перекрывая приточными струями (3) всю площадку, затем, после взаимодействия со льдом (4) и нижними слоями воздуха, поступает в верхнюю зону к вытяжным устройствам (5).

Опыт работы автора на действующих ледовых объектах показывает, что физические процессы, происходящие в объеме надо льдом, в действительности несколько иные.

Микроклимат в зоне ледовой площадки во многом определяется массивом льда, взаимодействующего с окружающим воздухом посредством тепломассообмена. Тепловая нагрузка на лед компенсируется за счет циркуляции хладоносителя в трубной системе охлаждения. Температура хладоносителя меняется в зависимости от нагрузки, за счет чего поддерживается постоянная температура ледовой поверхности, оптимальная для определенного вида спорта. В стационарном режиме надо льдом устанавливается поле температур и влагосодержаний, параметры которого формируются в зависимости от термодинамических характеристик воздушной среды у поверхности.

На рис. 2. представлена зависимость изменения температуры от высоты над ледовой поверхностью, полученная по результатам замеров, выполненных Лихтенштейном Э.Л. в объеме работ по исследованию температурных полей искусственных катков в 1970 г [1]. Работы проводились на экспериментальном катке, оборудованном в объеме Дворца спорта «Юбилейный» в г. Санкт-Петербурге. Графики отражают распределение температурных полей воздушной среды, граничащей с поверхностью льда и обеспечивающей теплообмен в условиях свободной и вынужденной конвекции. Ограждения (борт) вокруг ледовой площадки отсутствовали.

Из графиков следует, что у поверхности льда наблюдается слой воздуха со значительным градиентом, выше которого температура практически постоянна. Можно говорить о «пограничном слое», играющим важную роль в теории теплообмена.

В опытах Лихтенштейна Э.Л. режим вынужденной конвекции создавался включением вентиляторного агрегата с регулированием характеристик воздушных струй для обеспечения равномерной подвижности в объеме у ледовой поверхности. Работа вентилятора обеспечивала увеличенный общий уровень подвижности воздуха в объеме, прямого воздействия воздушных струй на ледовую поверхность не было. Из графиков рис. 2 видно, что при включении вентагрегата заметно уменьшается толщина пограничного слоя, что говорит об увеличении 
общей подвижности воздуха. При этом был отмечен также заметный рост результирующего коэффициента теплопередачи $\alpha$, что согласуется с принципами теории теплообмена.

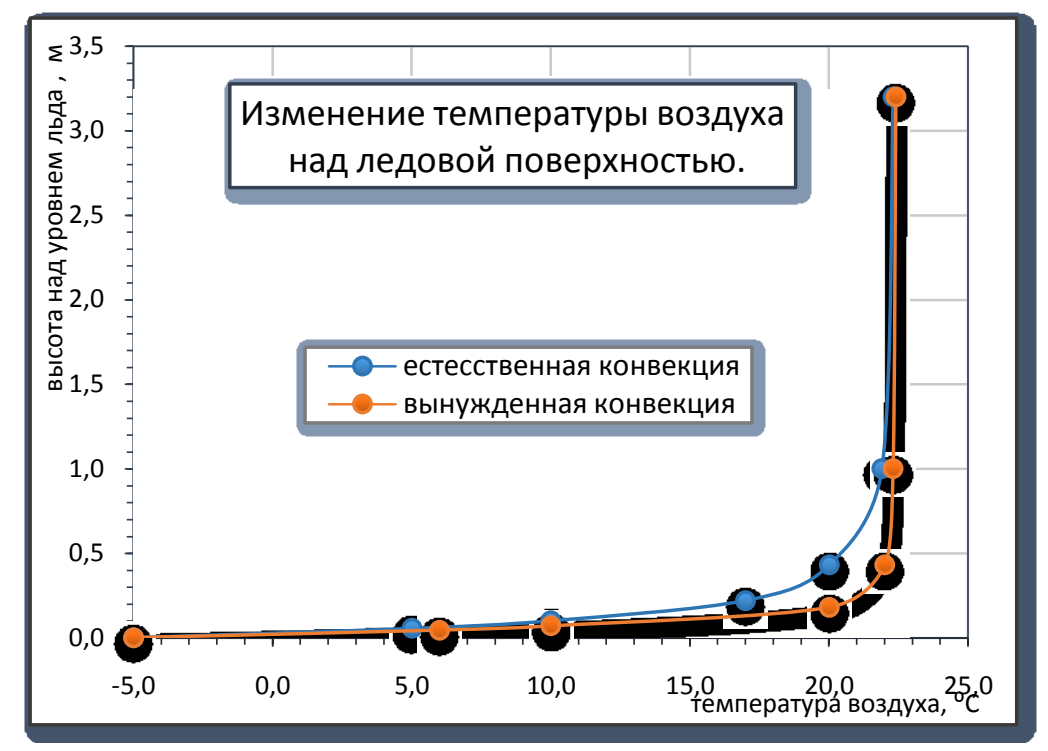

Рис. 2. Изменение температуры воздуха по высоте над ледовой поверхностью в условиях теплообмена в результате естественной и вынужденной конвекции при отсутствии ограждений по результатам Лихтенштейна Э.Л.

При наличии вокруг ледовой площадки достаточно высоких бортов условия для развития естественной конвекции внутри ограждения заметно затруднены. Современные конструкции хоккейных бортов вместе с защитными стеклами достигают высоты до 2,4 м по длинным сторонам площадки и до 3,2 м по коротким сторонам за воротами. В рабочее время конвективный тепло-массоперенос побуждает движение воздуха, вызванное системами кондиционирования, в немалой степени активностью спортсменов, а также иными факторами (открывание проемов в ограждении и пр.).

Лихтенштейном Э.Л. в объеме работ [1] также были проведены замеры температурного поля воздуха, сформировавшегося над ледовой поверхностью огражденного хоккейными бортами в демонстрационном зале Дворца. Измерения проводились в нерабочее время в отсутствии нагрузки и выключенных системах кондиционирования. Результаты измерений представлены на рисунке 3 в виде зависимости температуры от высоты надо льдом.

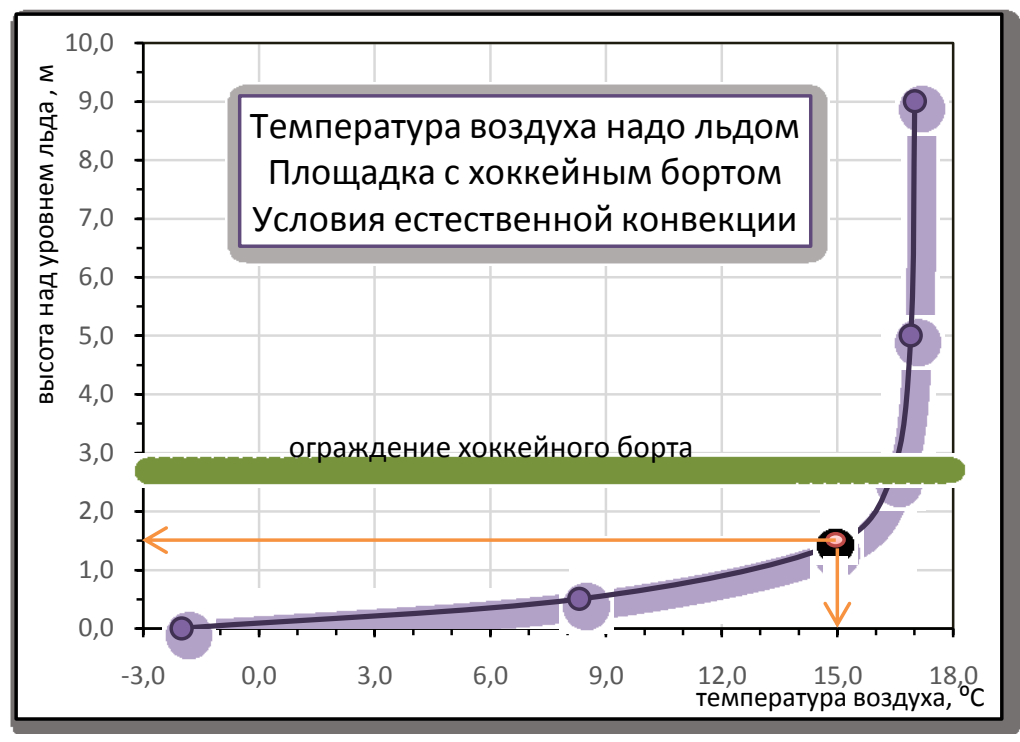

Рис. 3. Изменение температуры воздуха по высоте над ледовой поверхностью, огражденной хоккейными бортами в условиях естественной конвекции при общей подвижности воздуха по результатам Лихтенштейна Э.Л. 
На графике видно, что область с высоким градиентом температуры, меняющейся от $t_{8} \approx+17^{\circ} \mathrm{C}$ до температуры льда $t_{\pi}=-2{ }^{\circ} \mathrm{C}$, занимает весь объем в пределах ограждающих бортов (на графике высота бортов обозначена пунктиром). Выше градиент заметно уменьшается, распределение температуры определяется воздушными течениями общего объема, более интенсивными, чем в объеме бортов. Такая картина распределения температурных полей типична для крытых ледовых объектов [2,3]. Основная цель сохранения в относительном покое воздушных масс, граничащих с ледовой поверхностью - уменьшение интенсивности тепло-массообменных процессов льда с воздухом с уменьшением нагрузки на систему холодоснабжения, обеспечивающую поддержание льда, а также более продолжительному сохранению высокого качества ледовой поверхности. Кроме того, это позволяет поддерживать более низкую температуру воздуха на расчетной высоте 1,5 м, более комфортную для спортсменов - хоккеистов, чем средняя температура в объеме (на графике $-+15^{\circ} \mathrm{C}$ при $+17^{\circ} \mathrm{C}-$ для выше расположенного объема)

Рассмотрим другую схему распределения воздуха в объеме зала, реализованную в одном из функционирующих крытых катков. Зал имеет размеры 66*37 м при высоте около 13,5м. В зале располагается стандартная ледовая площадка размером $60 * 30$ м, огороженная высокими хоккейными бортами. Зал используется для тренировочных занятий хоккеистов, постоянные места для размещения зрителей отсутствуют. Схема воздушных потоков в пространстве зала представлена на рис. 4.

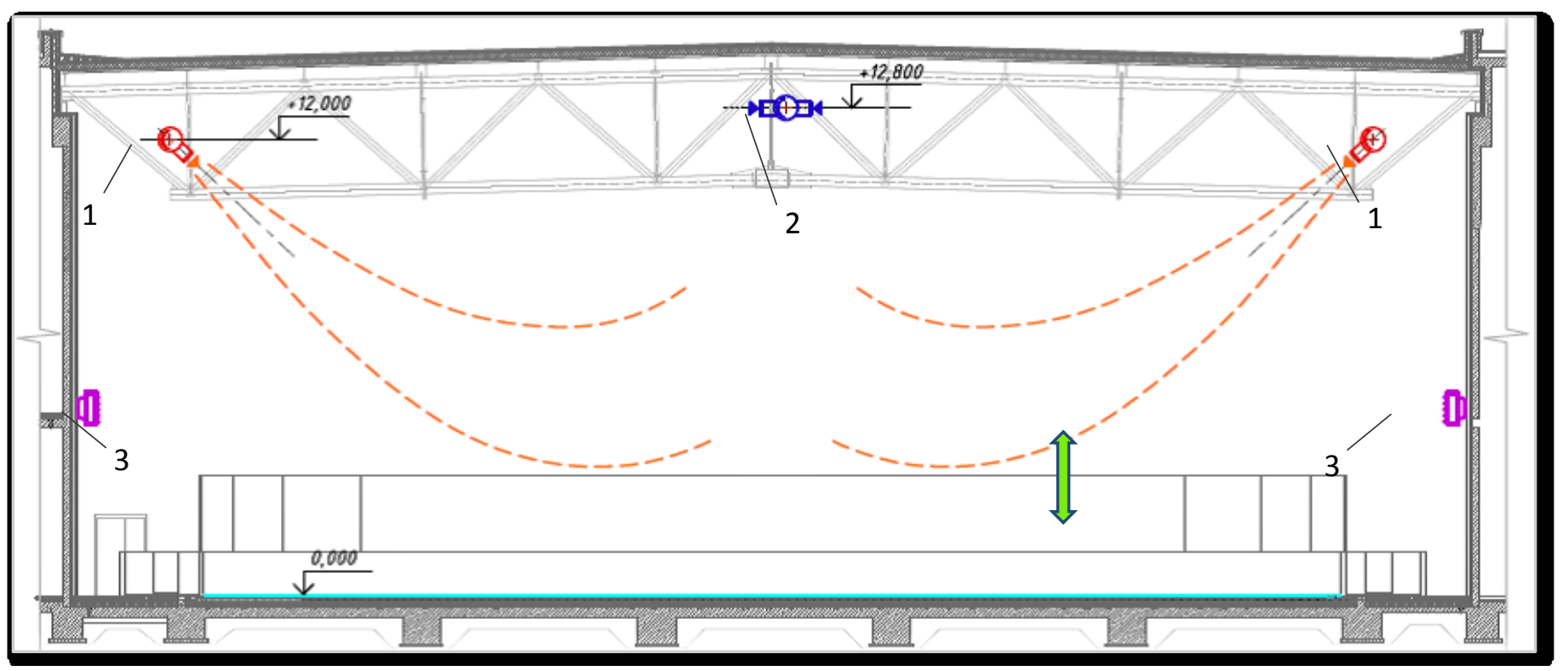

Рис. 4. Принципиальная схема распределения воздуха, альтернативный вариант.

На схеме: 1 - приточные воздуховоды, 2 - вытяжной воздуховод, 3 - воздушно-отопительные агрегаты

При кажущемся сходстве с рис. 1, выполненная схема является принципиально иной. Воздух, приготовленный в центральном кондиционере, подается в зал из дальноструйных сопел под углом около $45^{\circ} \mathrm{C}$ к горизонту. Температура подаваемого воздуха на несколько градусов выше, чем средняя температура в объеме. В зале наблюдается круглогодичный отрицательный тепловой баланс и система выполняет функции отопления совместно с воздушно-отопительными агрегатами, расположенными по периметру.

Нагретая воздушная струя в более холодном объеме подвержена действию архимедовых сил. Температура на выпуске поддерживается такой, чтобы струя всплывала на высоте 3-4 метра (ось струи) над уровнем льда, не касаясь слоев воздуха непосредственно над ледовой поверхностью.

Автором выполнены замеры температурного и влажностного полей в одной из характерных мест ледовой площадки (на рис. 4 обозначено 〈Џ). Ось ближайшей воздушной струи, в том числе от ближайшего отопительного агрегата, располагается достаточно далеко, прямое воздействия на зону льда отсутствует. Результаты замеров отражены на рисунке 5. 

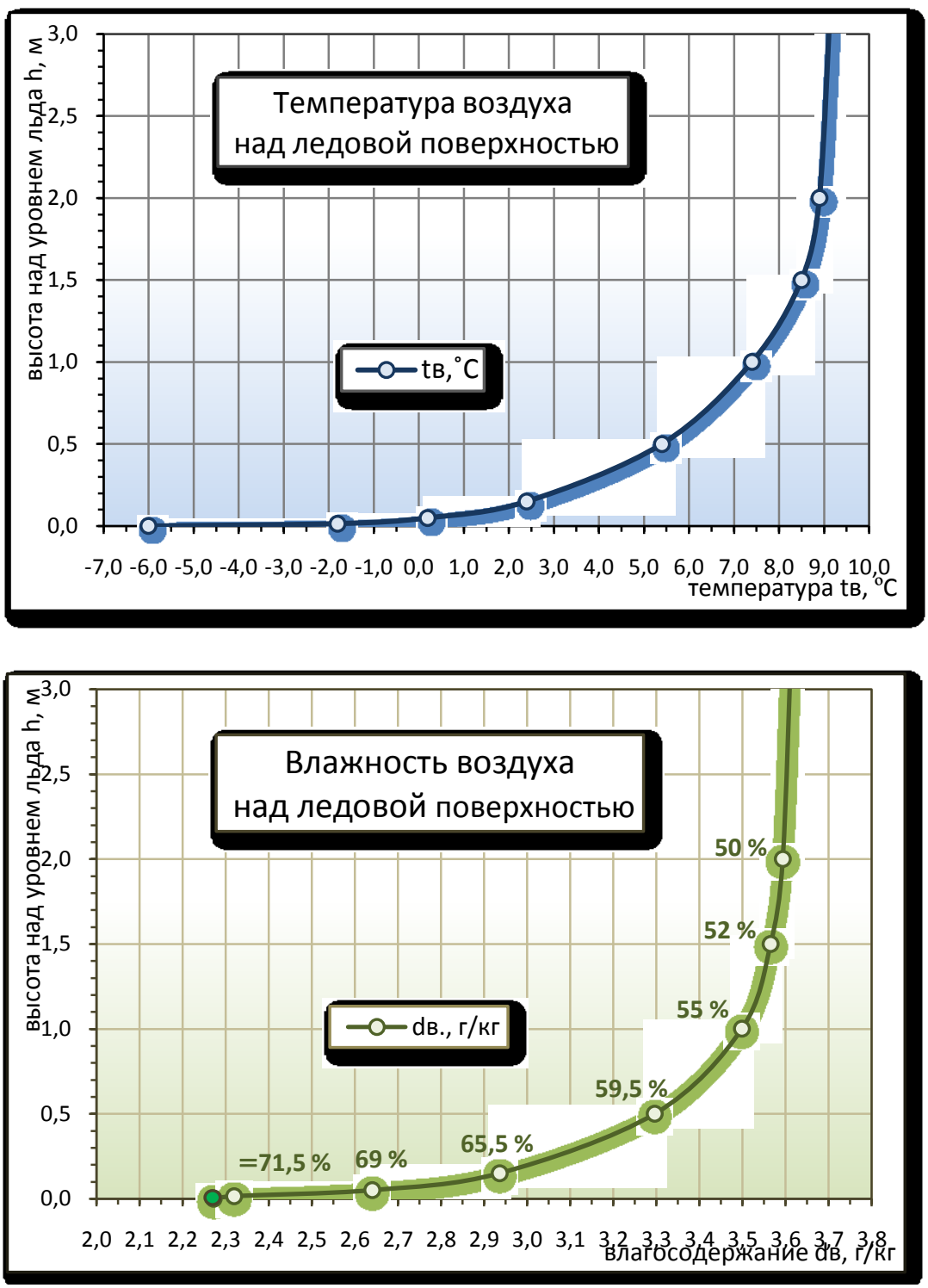

Рис. 5. Изменение температуры и влагосодержания (относительной влажности) воздуха по высоте над ледовой поверхностью, огражденной хоккейными бортами в условиях действующего ледового катка при работающей системе кондиционирования воздуха по результатам автора (Схема распределения воздуха - рис. 4)

График изменения температуры подобен рассмотренным выше. Влагосодержание воздуха по высоте над ледовой поверхностью распределяется также подобным образом. Результаты отражают интенсивность массобмена между воздухом и льдом.

Значения влагосодержания воздуха надо льдом по всей высоте больше, чем соответствующее состоянию насыщения у льда (на графике обозначено «ด»). Казалось бы, по мере приближения к поверхности, воздух должен охладиться до точки росы и начнется объемная конденсация, однако, по замерам нигде воздух не достигает состояния насыщения ( $\boldsymbol{\varphi}=100 \%)$, а значит конденсация в объеме отсутствует.

Конденсация на поверхности льда всегда сопровождает теплообмен, если парциальное давление водяных паров в пограничном слое больше давления насыщения, соответствующего параметрам льда, а значит присутствует и в нашем случае. Более подробно эти процессы описаны в [5]. Распределение влагосодержания по высоте в слое воздуха у льда определяется массопереносом водяных паров к поверхности. Графики распределения температуры и влагосодержания (рис.5) подобны, что подтверждает постулат о «тройной аналогии»[4] между процессами переноса импульса, тепла и примесей в процессе тепломассообмена, в качестве «примеси» выступает водяной пар, определяющий влажность воздуха.

Наиболее действенный способ уменьшения объема конденсации - снижение интенсивности движения воздуха у поверхности льда с попутным ослаблением теплообмена [7].

В процессе наладки системы воздухораспределения на объекте были зафиксированы нерасчетные увеличенные расходы на нескольких соплах, в результате чего приточные струи «пробивали» до ледовой 
поверхности. Не смотря на умеренные значения влагосодержания воздуха в струях - 3,6-3,7 г/кг, в этих местах были отмечены пятна повышенного инееобразования. Это подтверждает значимое влияние подвижности воздуха вблизи поверхности на интенсивность тепломассообмена и на состояние ледового массива.
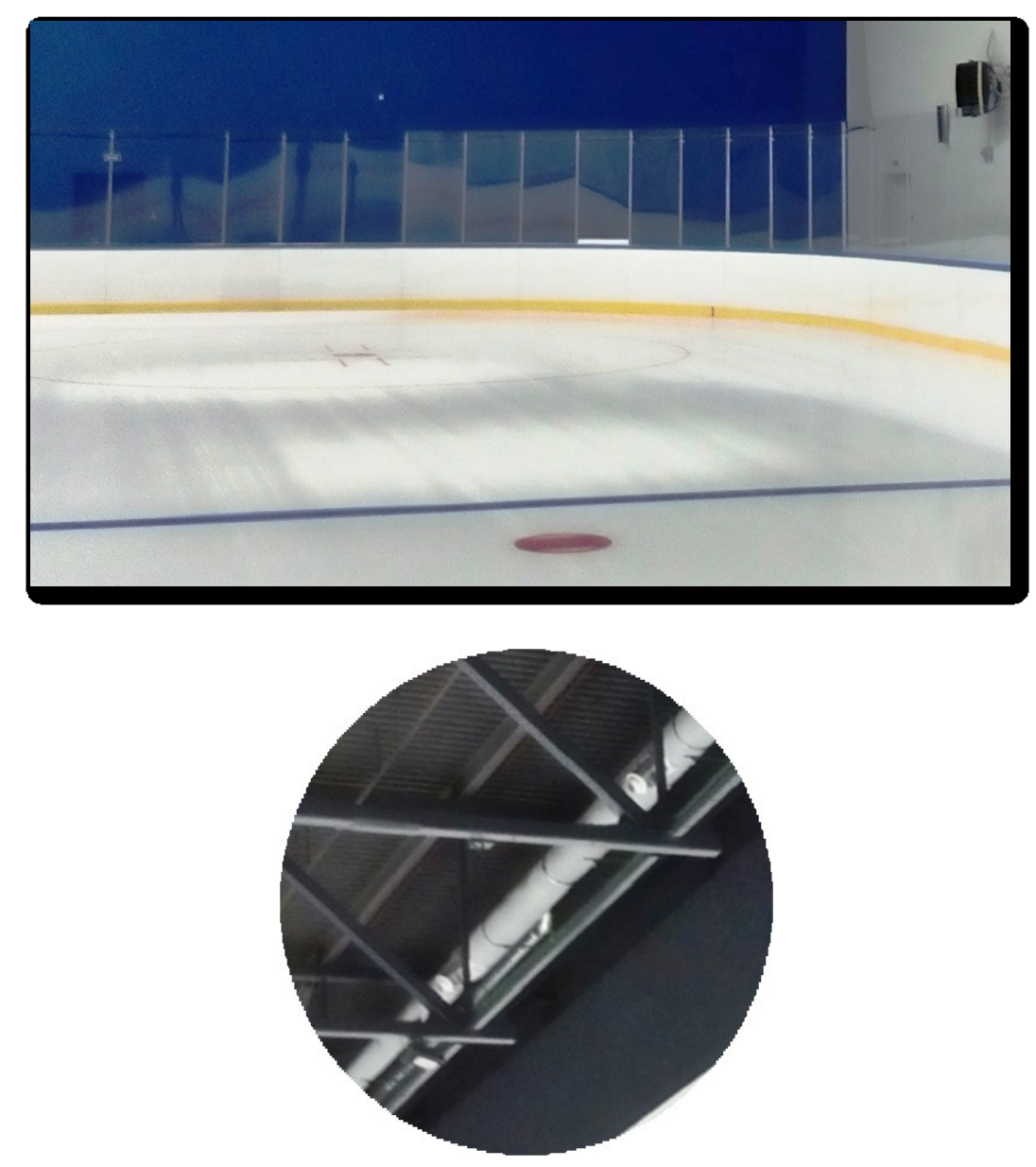

Рис. 5. Пятна инея на поверхности льда в результате увеличенной подвижности воздуха при нерасчетном расходе в струях из сопел, вызывающей интенсивную конденсацию влаги

После приведения расходов на сопла к расчетным значениям с ликвидацией прямого воздействия воздушных струй на лед, пятна исчезли, поверхность приобрела равномерную глянцевую фактуру.

Расчет воздушных струй выполняется на основе методик [6], [8], расчетная схема представлена на рис. 6. 


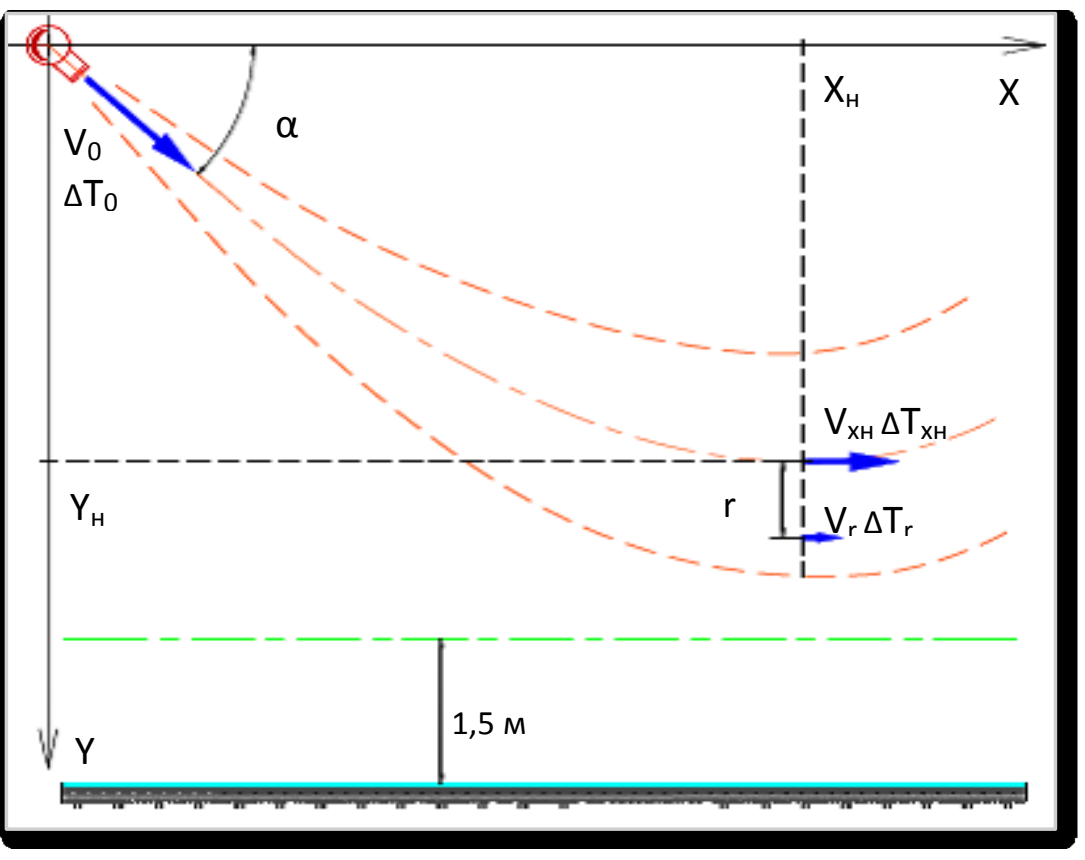

Рис. 6. Расчетная схема воздушной струи

Геометрическая характеристика воздушной струи, м:

$$
H=\sqrt{\frac{m^{2}}{n} \frac{T_{\infty}}{g} \frac{v_{o}^{2} \sqrt{F_{o}}}{\Delta T_{o}}}
$$

где: $m$ - аэродинамическая характеристика струи [6], скоростной коэффициент воздухораспределителя [8], $n-$ тепловая характеристика струи [6], температурный коэффициент воздухораспределителя [8], $T_{\infty}$ - температура воздуха в объеме, К, $\Delta T_{o}$ - избыточная температура на выпуске из сопла, К $v_{o}$ - скорость на выпуске, м/с, $F_{o}-$ площадь выпуска сопла, м², $g$ - ускорение свободного падения.

Для выпуска нагретого воздуха к обслуживаемой зоне сверху вниз под углом $\alpha$ координаты оси траектории струи связаны соотношением [8]:

$$
y=x \tan \alpha-\frac{x^{3}}{3 H^{2} \cos \alpha^{3}}
$$

где: $x, y$ - координаты вдоль горизонтальной и вертикальной осей с началом в отверстии выпуска при вертикальной оси, направленной вниз.

Проекция скорости на оси струи на горизонтальную ось в зависимости от координаты $x$ :

$$
v_{x}=\frac{m v_{o} \sqrt{F_{o}} \cos \alpha}{x} \sqrt{\cos \alpha^{2}+\left(\sin \alpha-\left(\frac{x}{H \cos \alpha}\right)^{2}\right)^{2}}
$$

Избыточная температура на оси :

$$
\Delta T_{x}=\frac{n \Delta T_{o} \sqrt{F_{o}} \cos \alpha}{x}
$$

Скорость в произвольной точке поперечного сечения струи :

$$
v_{r}=v_{x} e^{-\frac{1}{2}\left(\frac{r}{c x}\right)^{2}}
$$

где: $r$ - расстояние от оси струи до точки в поперечном сечении, $c$ - экспериментальная константа $=0,082[6]$. 
Избыточная температура в произвольной точке поперечного сечения:

$$
\Delta T=\Delta T_{x} e^{-\frac{\sigma}{2}\left(\frac{r}{c x}\right)^{2}}
$$

где: $\sigma$ - экспериментальная константа $=0,8[6]$.

Низшая точка траектории струи, после которой струя всплывает, имеет координаты:

$$
\begin{gathered}
x_{H}=H \cos \alpha \sqrt{\sin \alpha} \\
y_{H}=\frac{2}{3} x_{H} \tan \alpha
\end{gathered}
$$

В рассматриваемом зале приточный воздух в количестве $12400 \mathrm{~m}^{3} / \mathrm{\varphi}$ подается 20 соплами, расположенными 2 рядами - по 10 с каждой длинной стороны зала (рис. 4). Расход на 1 сопло составляет 620 $\mathrm{m}^{3} /$ ч. При эффективной площади выпуска $F_{0}=0,0154 \mathrm{~m}^{2}$ скорость на выходе из сопла $v_{0}=11,2 \mathrm{~m} / \mathrm{c}$. Воздух с температурой $+22{ }^{\circ} \mathrm{C}$ подается под углом $47^{\circ}$ к горизонту. При средней температуре в объеме $+14{ }^{\circ} \mathrm{C}$ избыточная температура на выпуске $\Delta T=8 \mathrm{~K}$.

Для струи из сопла с $m=6,88, n=6,2$ [6] геометрическая характеристика, рассчитанная по формуле (1) составит: $H=20,8$ м. Координаты низшей точки оси струи перед всплытием $(7,8): x_{H}=12,1$ м, $y_{H}=8,7$ м. При расположении сопел на отметке +12.0 м точка располагается на высоте 3,3 м надо льдом. Скорость воздуха в этой точке (3) совпадает с проекцией на горизонтальную ось: $v_{x_{H}}=0,37 \mathrm{~m} / \mathrm{c}$. Соответствующая избыточная температура (4): $\Delta T_{x_{H}}=0,34 \mathrm{~K}$.

В объеме ледовой площадки принято контролировать параметры на высоте 1,5 м надо льдом. Скорость воздуха и избыточная температура в струе на этом уровне при удалении расчетной точки от оси $r=1,81 \mathrm{M}$, составят (5,6): $v_{1,81}=0,07 \mathrm{~m} / \mathrm{c}, \Delta T_{1,81}=0,09 \mathrm{~K}$.

По рассчитанным значениям можно судить об отсутствии прямого воздействия воздушной струи на рабочую зону. В этом случае имеет место «сосредоточенная подача» воздуха [8], когда рабочая зона омывается обратным потоком. Максимальная скорость движения воздуха в таком потоке:

$$
v_{x}=K v_{o} \frac{\sqrt{F_{o}}}{\sqrt{F_{n}}}
$$

где: $K$ - коэффициент, зависящий от количества распределителей в ряду [8], для нашего случая $K=0,9, \quad F_{n}-$ поперечная площадь помещения, приходящая на 1 струю, м².

Для 10 струй [8] $K=0,9, \quad F_{n}=6,6^{*} 13,5=89,1$ м $^{2}$ максимальная скорость в полутораметровой зоне над поверхностью льда, рассчитанная по обратному потоку: $v_{x}=0,13$ м/с, что не превышает максимальные значения, установленные нормативной документацией [9].

При расчетных расходах система автоматики приточно-вытяжной установки поддерживает постоянной величину избыточной температуры на выпуске из сопла, соответственно и геометрические характеристики струйных течений в объеме. При этом влияние на ледовую поверхность приточных струй минимизировано. Для увеличения же интенсивности вентиляции в объеме у самого льда, достаточно уменьшить величину перегрева на притоке. Так при температуре подачи $+19^{\circ} \mathrm{C}$ (избыточная температура $5 \mathrm{~K}$ ) скорость воздуха на уровне нижней точки оси струи (1,0 м надо льдом) составит: $v_{x н}=0,29 \mathrm{~m} / \mathrm{c}$, непосредственно у поверхности льда: $v_{1,0}=0,21 \mathrm{~m} / \mathrm{c}$. При этом расчетные значения не превышают максимальные нормативные значения [9], однако такой режим рекомендуется устанавливать только в случае обоснованной необходимости, например для усиленного вентилирования после применения льдообрабатывающего оборудования с двигателями внутреннего сгорания $[10]$.

\section{Литература}

1. Лихтенштейн Э.Л. Исследование температурного поля искусственного катка: диссертация на соискание ученой степени кандидата технических наук //Л: ЛТИХП, 1970.

2. Pennanen AS, Salonen RO, Aim S, Jantunen MJ, Pasanen P. Characterization of

Air Quality Problems in Five Finnish indoor Ice Arenas. Journal of the Air \& Waste Management Association. 1997. 47: 1079-1086. 
3. Ouzzane M, Sunye R, Zmeureanu R, Giguere D, Scott J, Bellache O. (2006). Cooling Load and Environmental Measurement in a Canadian Indoor Ice Rink. ASHRAE Transactions. V.112, P.2

4. Теоретические основы хладотехники. Часть 2. Тепломассообмен // Богданов С.Н., Бучко Н.А, Гуйго Э.Й. и др. - М: Колос, 1994. -368c.

5. Русаков С.В. Оценка влияния влажности на качество микроклимата в зале ледового катка и на состояние ледовой поверхности // Научный журнал НИУ ИТМО. Серия «Холодильная техника и кондиционирование» №2, 2015

6. Шепелев И.А. Аэродинамика воздушных потоков в помещении. // М: Стройиздат, 1978. -144 с.

7. Коченков Н.В., Мотрев А.А., Коченков В.Н. Энергоэффективное функционирование систем кондиционирования и отопления для встроенного помещения // Вестник Международной академии холода. 2016. № 4. С.47-52.

8. Внутренние санитарно-технические устройства . В3 ч. Ч.3. Вениляция и кондиционирование воздуха. Кн.2 / Б.В.Баркалов, Н.Н.Павлов, С.С.Амирджанов и др.; Под ред. Н.Н.Павлова и И.Ю.Шиллера -4-е изд. , перераб. и доп. - М.: Стройиздат. 1992.-416 с. : ил.-(Справочник проектировщика)

9. СП 31-112-2007. Физкультурно - спортивные залы. Часть 3. Крытые ледовые арены. //M: 2008.

10. Русаков С.В. Оценка влияния работы льдоуборочного комбайна на качество воздуха в зале крытого ледового катка.// Научный журнал НИУ ИТМО. Серия «Холодильная техника и кондиционирование» №4, 2016

\section{References}

1. Lihtenshtejn E.L. Issledovanie temperaturnogo polya iskusstvennogo katka: dissertaciya na soiskanie uchenoj stepeni kandidata tekhnicheskih nauk //L: LTIHP, 1970.

2. Pennanen AS, Salonen RO, Aim S, Jantunen MJ, Pasanen P. Characterization of Air Quality Problems in Five Finnish indoor Ice Arenas. Journal of the Air \& Waste Management Association. 1997. 47: 1079-1086.

3. Ouzzane M, Sunye R, Zmeureanu R, Giguere D, Scott J, Bellache O. (2006). Cooling Load and Environmental Measurement in a Canadian Indoor Ice Rink. ASHRAE Transactions. V.112, P.2

4. Teoreticheskie osnovy hladotekhniki. Chast 2. Teplomassoobmen // Bogdanov S.N., Buchko N.A, Gujgo EH.J. i dr. - M: Kolos, 1994. $-368 \mathrm{p}$.

5. Rusakov S.V. Ocenka vliyaniya vlazhnosti na kachestvo mikroklimata v zale ledovogo katka i na sostoyanie ledovoj poverhnosti // Nauchnyj zhurnal NIU ITMO. Seriya «Holodil'naya tekhnika i kondicionirovanie». № 2, 2015.

6. Shepelev I.A. Aehrodinamika vozdushnyh potokov v pomeshchenii. // M: Strojizdat, 1978. -144 p.

7. Kochenkov N.V., Motrev A.A., Kochenkov V.N. Energy efficient operating modes for central air conditioning and heating systems in an integral room // Vestnik Mezhdunarodnoi akademii kholoda. 2016. № 4. p. 47-52.

8. Vnutrennie sanitarno-tekhnicheskie ustrojstva . V3 ch. CH.3. Venilyaciya i kondicionirovanie vozduha. Kn.2/ B.V.Barkalov, N.N.Pavlov, S.S.Amirdzhanov i dr.; Pod red. N.N.Pavlova i I.YU.SHillera -4-e izd. , pererab. i dop. - M.: Strojizdat. 1992.-416 p. : il.-(Spravochnik proektirovshchika)

9. SP 31-112-2007. Fizkul'turno - sportivnye zaly. Chast' 3. Krytye ledovye areny. //M: 2008.

10. Rusakov S.V. Ocenka vliyaniya raboty l'douborochnogo kombajna na kachestvo vozduha v zale krytogo ledovogo katka.// Nauchnyj zhurnal NIU ITMO. Seriya «Holodil'naya tekhnika i kondicionirovanie». № 4. 2016. 